\title{
Horner's syndrome as a reason for consultation in a patient with breast tumor - A case report
}

\section{Síndrome de Horner como motivo de consulta en paciente con tumor de mama. Reporte de caso}

\author{
Verónica Cristina Martínez-Mayorquín ${ }^{1 *}$, David Lozano-Elizondo², Rosa E. Moreno-Anda ${ }^{3}$, \\ Luis M. Pesci-Eguía², Karina L. Miranda-Sánchez ${ }^{1}$ and Irene González-Olhovich ${ }^{2}$
}

${ }^{1}$ Instituto Nacional de Neurología y Neurocirugía Manuel Velasco Suárez; ${ }^{2}$ Neuro-ophthalmology Department, Instituto Nacional de Neurología y Neurocirugía Manuel Velasco Suárez; ${ }^{3}$ Anterior Segment Department, Instituto Nacional de Rehabilitación Dr. Guillermo Ibarra. Mexico City, Mexico

\begin{abstract}
Horner's syndrome consists of an injury to the sympathetic pupillary pathway, Described with the triad: ptosis, miosis, and anhidrosis. Recognizing the signs of this syndrome, their levels of injury and causes are of paramount importance to the clinician. Case: A 38-year-old female patient presented with ptosis of the upper eyelid, right eye, 2 months of evolution, growth of axillary ganglion 4 years ago, also cough of 6 -month duration, and $6 \mathrm{~kg}$ weight loss in 3 months. Exploration: mild ptosis, greater anisocoria in the dark, and right miosis. Systemic exploration: right breast tumor of $6 \mathrm{~cm}$, adhered to deep planes. The patient was referred to an oncological center. This case is important because there is a widespread of prevention programs; however, there are still people who continue to hide their diseases, and we must not forget that the eyeball is a key point to detect systemic diseases.
\end{abstract}

Key words: Horner's Syndrome. Miosis. Ptosis. Breast.

\section{Resumen}

El síndrome de Horner consiste en una lesión de la vía pupilar simpática. Descrito con la triada: ptosis, miosis y anhidrosis. Reconocer los signos de este síndrome, sus niveles de lesión y las causas es de suma importancia. Caso: Paciente mujer de 38 años de edad, acude por ptosis del párpado superior del ojo derecho de 2 meses de evolución, hace 4 años ganglio axilar, hace 6 meses aparición de tos; pérdida de peso: $6 \mathrm{~kg}$ en 3 meses. Exploración: ptosis leve, anisocoria mayor en la oscuridad, miosis derecha. Se realiza exploración: tumoración en la mama derecha de $6 \mathrm{~cm}$, adherida a planos profundos. Se envía al centro de cancerología. Este caso toma importancia, ya que actualmente existe una amplia difusión de programas de prevención, sin embargo, aún hay personas que siguen escondiendo sus padecimientos, no debemos olvidar que el globo ocular es punto clave para detectar enfermedades sistémicas.

Palabras clave: Síndrome de Horner. Miosis. Ptosis. Mama.

Correspondence:

*Verónica Cristina Martínez-Mayorquín,

Juan Manuel, 1500

Col. Ladrón de Guevara

Date of reception: 12-06-2017

Date of acceptance: 22-11-2017

DOI: 10.24875/RMOE.M19000078
Available online: 01-09-2019 Rev Mex Oftalmol (Eng). 2019;93(5):36-39

www.rmo.com.mx 2604-1731/O 2017 Sociedad Mexicana de Oftalmología. Published by Permanyer México SA de CV. This is an Open Access article under the CC BY-NC-ND license (http://creativecommons.org/licenses/by-nc-nd/4.0/). 


\section{Introduction}

Horner's syndrome was first described in 1869 by the Swiss ophthalmologist Johann Friedrich Horner. Classically, it is due to a sympathetic lesion and shows a triad of ptosis, miosis, and anhidrosis, depending on the level where the lesion is located. The triad is not always complete; up to $10 \%$ of cases have no ptosis. There are several causes such as carotid dissection, tumors that compromise the pulmonary apex and hypothalamic lesions, among others. It is important to mention that it can be a manifestation or sign of metastatic disease. Recognizing the signs of this syndrome, the levels of injury and its implications are of utmost importance for the clinician.

There are pharmacological tests for diagnosis that is aimed to recognize anisocoria (which is clinically significant when there is a difference of $1 \mathrm{~mm}$ or more), to identify if it is an autonomic or intrinsic pupillary problem, and to locate a lesion at the postganglionic level. However, there are very suggestive and localizing signs that allow diagnosis. In addition, it is important to interrogate accompanying symptoms to locate the level of the lesion.

Pupillary symptoms are usually subtle, since anatomically, the pupil has a nervous control with a 30:1 ratio of parasympathetic and sympathetic fibers. This is why anisocoria is not evident under normal light conditions. We can frequently find Horner's syndrome associated with ipsilateral "isolated" sixth cranial nerve palsy. It is essential to explore patients carefully and under different light conditions, to classify the findings and make a more accurate topographic diagnosis.

\section{Clinical case}

A 38-year-old woman was sent to the Neuro-ophthalmology Department of the Instituto Nacional de Neurología y Neurocirugía Manuel Velasco Suárez due to a 2-month history of upper eyelid ptosis of the right eye.

\section{Initial presentation and history of the current condition}

The patient refers that 4 years ago, she presented an axillary lymph node enlargement, and 6 months ago, she started with dry cough and cervical lymph nodes enlargement (approximately 6 stony hard, non-mobile, and irregular nodes) with a weight loss of $6 \mathrm{~kg}$ in 3 months.

\section{Findings}

Mild ptosis in the right eye $(2 \mathrm{~mm}$ compared with the left eye), greater anisocoria under dim light with right miosis, right eyelid opening of $9 \mathrm{~mm}$, margin reflex distance 1 (MRD 1) of $2 \mathrm{~mm}$; MRD 2 of $7 \mathrm{~mm}$. Eyelid opening of the left eye of $12 \mathrm{~mm}$, MRD 1 of $4 \mathrm{~mm}$, MRD 2 of $8 \mathrm{~mm}$ (Fig. 1). Right pupil diameter of $3 \mathrm{~mm}$ and left pupil diameter of $5 \mathrm{~mm}$, with normal response to light in both eyes, conserved consensual light reflex (Fig. 2). The patient was asked to discover her torso, observing a tumor in the right breast that alters the structure with a complete loss of anatomy. In addition, tumor is palpated in deep planes and its extension cannot be delimited; the skin has a "peau d'orange" appearance (Fig. 3). A contrast computed tomography of the thorax was requested, and the patient was sent to a cancer center for proper management. However, the patient did not attend the cancer center and did not come back to our department.

\section{Discussion}

In Horner's syndrome, clinical signs may be subtle, and it is not common that patients show the classic triad. If we associate clinical signs and symptoms, we can locate the lesion and direct the diagnostic approach. Regarding pharmacological tests, without diminishing the importance of their usefulness, in our center, they are of limited use, since sometimes they are not available, and false positives and negatives have been observed 1 .

Although it is true that some drug tests such as cocaine, hydroxyamphetamine, and apraclonidine are an important aid for diagnosis, the location of the lesion can be determined by the classic clinical signs and the accompanying data. It is important to remember that in this disorder, the pupillary light reflex is normal ${ }^{1,2}$. There are no infallible pharmacological tests to determine the location of the lesion.

There are other reported cases secondary to different etiologies, such as thyroid nodules, which sometimes remit after the surgical treatment of the underlying disease ${ }^{2}$. Regarding the clinical case presented, there are some published reports of metastatic breast cancer that presents as Horner's syndrome ${ }^{3}$. In our case, the patient did not have a previous diagnosis of malignancy.

Other causes of Horner's syndrome are internal carotid artery dissection, as a result of an accident and/ or trauma in patients under 45 years of age, which also 


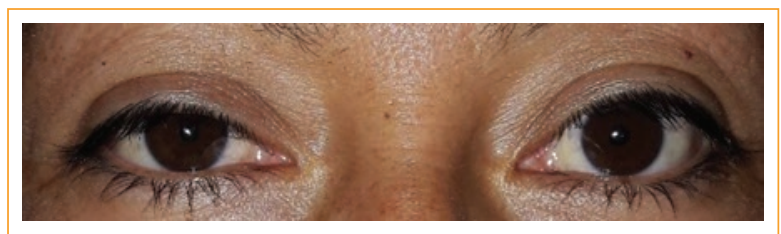

Figure 1. Exploration with light and eyelid aperture. Right eye: $9 \mathrm{~mm}$, margin reflex distance 1 (MRD 1): $2 \mathrm{~mm}$. MRD 2: $7 \mathrm{~mm}$. Left eye aperture: $12 \mathrm{~mm}$. MRD 1: $4 \mathrm{~mm}$. MRD 2: $8 \mathrm{~mm}$. Anisocoria.

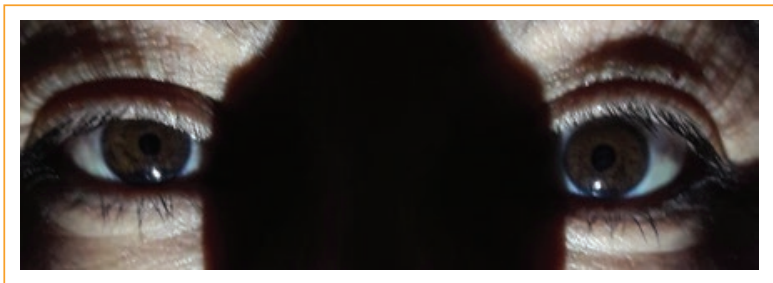

Figure 2. Greater anisocoria in the dark. Right pupil diameter: $3 \mathrm{~mm}$. Left pupil diameter: $5 \mathrm{~mm}$. Normal response to light.

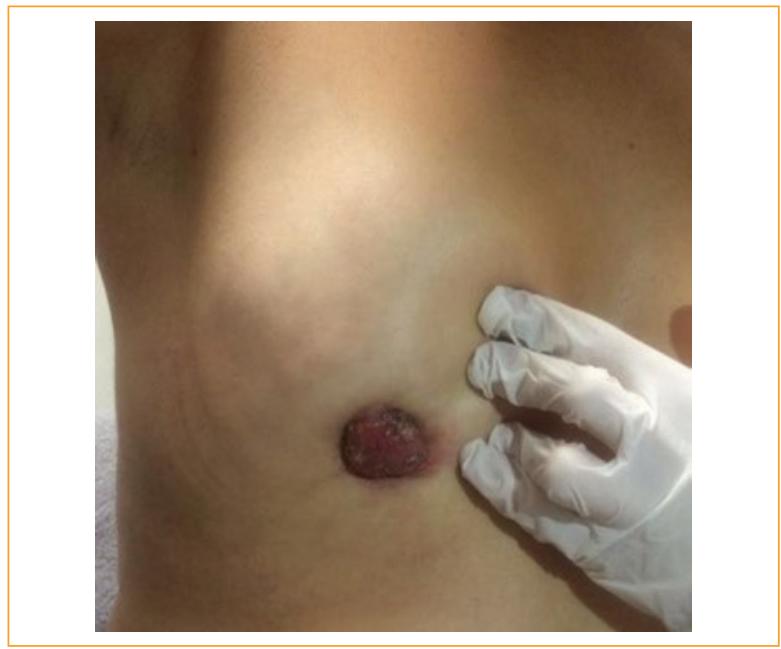

Figure 3. Right breast tumor.

causes $10-20 \%$ of cases of ischemic stroke. The diagnosis should be suspected in cases of Horner's syndrome with headache, neck pain, and signs of retinal or brain ischemia 4 .

Other less common causes of sympathetic pupillary pathway lesions are inflammatory diseases of the central nervous system, such as neuromyelitis optica or Devic's disease. There is a case report of a 58-year-old woman who presented Horner's syndrome with contralateral hemianesthesia, confirmed with $0.5 \%$ apraclonidine and positive titers of anti-aquaporin- 4 antibodies ${ }^{5}$.

Horner's syndrome can be classified into three groups according to the location of the lesion - central, which can occur in lesions of the hypothalamus and brainstem and spinal cord that affect the sympathetic pathway. The entities most frequently observed are Wallenberg syndrome and syringomyelia, among others. Concomitant neurological findings may suggest this type of injury. The preganglionic type may be the result of radicular lesions of the spinal cord, brachial plexus, trauma, lesions of the pulmonary apex, or mediastinal tumors. The postganglionic lesion is related to diseases of the internal carotid artery, cranial floor, cavernous sinus, superior orbital fissure, and orbital apex, among others. Enophthalmos is apparent due to inverse ptosis, since there is loss of the sympathetic tone of the inferior Müllers muscle analog or inferior tarsal muscle ${ }^{6}$.

In case of third-order neuron damage, the sympathetic fibers responsible for the sudomotor function of the lower portion of the face are separated from the oculosympathetic pathway before the superior cervical ganglion; therefore, anhidrosis will rarely be observed in this distribution in postganglionic lesions, so sweating should be explored in the upper third of the face ${ }^{7}$. We can explore this in a simple way by applying talcum powder on the face and asking the patient to perform physical activity to see if any side of the face does not show sweating or in a more familiar way using iodine.

Cocaine is a sympathomimetic that blocks norepinephrine reuptake. While normal pupils dilate, in case of a sympathetic lesion, they do not dilate since the pathway of the three neurons has been interrupted. Topical apraclonidine (alpha-2-adrenergic agonist) is another drug used for testing. It has been shown that this drug reverses anisocoria by dilating the altered pupil and not having an effect on the normal pupil. Topical $1 \%$ hydroxyamphetamine can also be used to confirm third neuron or postganglionic injury. Hydroxyamphetamine stimulates the release of norepinephrine at the presynaptic terminal button. In the first or second-order neuron injuries, the presynaptic button is intact, and the pupil dilates; this is not the case for third-order neuron injuries ${ }^{8-10}$.

The pupils should always be carefully evaluated under different light conditions and with adequate light, observing if there is anisocoria or alteration of the pupillary reflexes. If we detect abnormal responses, we should assess whether they are unilateral or bilateral and accompanied by other symptoms; furthermore, the 
patient must be adequately interrogated. If we follow these steps, we are less likely to miss important signs for a crucial diagnosis.

\section{Conclusion}

In this article, we reviewed the general characteristics and the different causes of Horner's syndrome. In the case of our patient, it is important to note that the reason for consultation was "mild ptosis," without mentioning a diagnosis of malignancy or any underlying disease. Interrogation was difficult since the patient had an introverted behavior and denied other signs and symptoms. However, when we followed the affected lymphatic chain, the axillary lymph node involvement was observed. As axillary lymph node enlargement in a young woman is suggestive of a malignancy originated in the breast, a chest examination was performed that showed a lesion highly suggestive of breast cancer.

This case is relevant, since it is currently thought that in our society, there is vast information and sufficient prevention programs; however, today, there are still people who continue to hide their diseases until they reach advanced stages, metastatic disease, or death. That is why if we detect any findings, we must ask, investigate, observe, and make an exhaustive medical history.

Despite explaining to the patient the importance of going urgently to the cancer center, ordering imaging studies and giving her a new appointment in our service, the patient did not return and was lost to follow-up.

From a neuro-ophthalmological point of view, we must not forget that behind each eyeball, there is a patient with a whole system that works together and that many disorders may have their first manifestation in the visual system.

It is our obligation to perform a complete examination and an adequate medical history to find the etiology.
Being aware of the function, sensitivity and specificity of the pharmacological tests for the detection of Horner's syndrome is indispensable, but this is no substitute for a well-carried out semiology.

\section{Ethical disclosures}

Protection of human and animal subjects. The authors declare that no experiments were performed on humans or animals for this study.

Confidentiality of data. The authors declare that they have followed the protocols of their work center on the publication of patient data.

Right to privacy and informed consent. The authors have obtained the written informed consent of the patients or subjects mentioned in the article. The corresponding author is in possession of this document.

\section{References}

1. Davagnanam I, Fraser CL, Miszkiel K, Daniel CS, Plant GT. Adult Horner's syndrome: a combined clinical, pharmacological, and imaging algorithm. Eye. 2013;27:291-8

2. Coskun M, Aydogan A, Gokce C, Ilhan O, Ozkan OV, Gokce H, Oksuz H. Irreversible Horner's syndrome diagnosed by aproclonidine test due to benign thyroid nodule. Pak J Med Sci. 2013:29(1):224-6.

3. Zhou D, Ibrahim M, Malach D, Tomsak RL. Unusual Cause of Horner Syndrome Years After In Situ Ductal Carcinoma. Neuroophthalmology. 2016; 40(3):130-2.

4. Alonso Formento JE, Fernández Reyes JL, Envid Lázaro BM, Fernández Letamendi T, Yeste Martín R, Jódar Morente FJ. Horner's Syndrome 17 due to a Spontaneous Internal Carotid Artery Dissection after Deep Sea Scuba Diving. Case Rep Neurol Med.2016;2016:5162869.

5. Lovera L, Jay WM, Biller J. Horner Syndrome in a Case of Neuromyelitis Optica. Neuroophthalmology. 2014;38(2):78-81.

6. Jacob S, Patil SI. Heralding Extramedullary Blast Crisis: Horner's Syndrome with Brachial Plexopathy in a Patient with Chronic Myelogenous Leukemia. Case Reports in Medicine. 2016;2016:3015947.

7. Nasser BA, Mesned A, Moazamy YE, Kabbani MS. Horner's syndrome after paediatric cardiac surgery: case report and review of the literatura. Cardiology Young. 2015;25:569-72.

8. Mohyudin MN, Arshad FA, Anand N. Horner's síndrome as a presenting sign of metastatic testicular malignancy, JRSM Short Rep. 2011:2.23.

9. Manasa Sriraam L, Sundaram R, Ramalingam R, Ramalingam KK. Minor's Test: Objective Demonstration of Horner's Syndrome. Indian J Otolaryngol Head Neck Surg. 2015;67(2):190-2.

10. Rodríguez-Sánchez E, Vadillo JM, Herrera-Calo P, Marenco de la Fuente ML. Síndrome de Horner tras analgesia epidural para el parto. Informe de 3 casos. Rev Colomb Anestesiol. 2016;44(2):170-3. 